\title{
From abstraction to action: Making wellness practical during residency training
}

\author{
Daniel K. Ting, MD*; Jared Baylis, MD* \\ INTRODUCTION
}

In 2017, the Canadian Medical Association conducted a survey that found that more than one quarter of physicians are dissatisfied with their work-life balance and a tenth with their professional lives. ${ }^{1}$ Burnout is a term introduced in the 1970s to measure a depressed mental state related to occupation. ${ }^{2}$ Increasingly, our community in emergency medicine has identified burnout as a threat to our specialty. ${ }^{3,4}$

During residency training, trainees experience high rates of burnout. ${ }^{5}$ Residency is a formative period of time in which attitudes and habits towards work are built, for better or worse. In the current issue of CFEM, Taher et al. ${ }^{6}$ establish a set of 31 recommendations for training programs that compose a "minimum standard" of wellness goals. One substantial challenge will be translating these recommendations into concrete steps. In this editorial, we answer three key questions on the practicalities of implementing wellness in residency training.

\section{How can we integrate wellness curricula into already full academic schedules?}

Several aspects of a busy residency schedule contribute to burnout, including competing demands and a lack of autonomy over time management. ${ }^{5}$ Therefore, didactic curricula that consume additional time at the expense of practical wellness initiatives are generally poorly received by residents. Approximately one third of the recommendations from the Taher et al. position statement relate to establishing a wellness curriculum. This curriculum need not be separate from current residency-based activities nor does it require yet more time commitment.

Many residency programs organize annual resident retreats in which residents receive protected time from clinical duties to socialize and team build with their colleagues. Consider using this already protected time to focus on wellness topics. These events would be particularly well suited to the resiliency training recommendations such as hands-on sessions on tactical breathing and mental rehearsal of complex tasks.

Other simple strategies that educators can use to promote wellness outside of the academic schedule include establishing mentorship programs, as work-life balance is one of the most commonly discussed topics with mentors, ${ }^{7}$ and advocating for departmental funds to provide healthy snacks for residents and staff while on shift. ${ }^{4}$

\section{How can we foster a culture of vulnerability within training programs?}

Sharing day-to-day struggles, both personal and professional, can be a therapeutic antidote to burnout. However, encouraging honest dialogue about challenging situations in residency can be difficult within a medical culture that celebrates perfectionism. Fortunately, there are initiatives such as Ice Cream Rounds, which are small group sessions for residents to share a personal work-related story in a safe space. ${ }^{8}$ The goal is to trigger reflective practice, share practical wisdom, and cultivate meaningful interactions between residents. These types of interactive sessions can replace existing didactic content during academic days.

From the *Department of Emergency Medicine, University of British Columbia, Kelowna, BC.

Correspondence to: Dr. Daniel K. Ting, Department of Emergency Medicine, University of British Columbia, 2312 Pandosy St., Kelowna, BC V1Y 1T3; Email: daniel.ting@alumni.ubc.ca 


\begin{tabular}{|c|c|c|}
\hline Phrase & Rationale & Example \\
\hline $\begin{array}{l}\text { Quality } \\
\text { standard }\end{array}$ & $\begin{array}{l}\text { Declines opportunity in a respectful way that attributes } \\
\text { reason to other commitments rather than a lack of interest. }\end{array}$ & $\begin{array}{l}\text { "As much as I would like to participate, my current } \\
\text { commitments prevent me from doing the job to the standard } \\
\text { I hold myself to." }\end{array}$ \\
\hline $\begin{array}{l}\text { Use "And" } \\
\text { instead of } \\
\text { "But"14 }\end{array}$ & $\begin{array}{l}\text { Using the conjunction "But" can nullify the preceding clause, } \\
\text { whereas using the conjunction "And" can reject the } \\
\text { invitation clearly while affirming the relationship by showing } \\
\text { you appreciate the intention. }\end{array}$ & $\begin{array}{l}\text { "This project is extremely valuable, and I appreciate your } \\
\text { invitation. Recognizing that, it's important for me to be } \\
\text { honest that I cannot devote the necessary time." }\end{array}$ \\
\hline
\end{tabular}

Beyond group settings, there are also a number of strategies to build one's own personal level of comfort with vulnerability. Several residents have taken to authoring humanities articles to process, articulate, and share their narratives. ${ }^{9,10}$ Others have identified a close colleague as a "failure friend" 11 who understands the context and nuances of medicine, empathizes, and listens well. Having a failure friend provides an outlet to share feelings, which nurtures insight and self-growth. Other strategies include mindfulness about our inner dialogue. We are often our own harshest critics when it comes to making mistakes, and we ruminate about even small errors. Being mindful of this self-talk opens up an opportunity to replace negative inner dialogue with the type of compassionate language that one would use to console a good friend. ${ }^{11}$

\section{How do we learn to say no when saying yes has gotten us to where we are?}

One aspect of the wellness position statement that is left unaddressed is that many of the factors leading to worklife imbalance are self-imposed and would likely persist even if all of the recommendations were implemented successfully.

Those who walk the path of medicine are conditioned to be overachievers. Through the process of medical school admission and the residency match, many learn that academic and professional success is predicated on the ability to take on additional work, for example, extracurricular projects, volunteer positions, and leadership roles. Selection of individuals who excel at these traits can distill attributes that are often positive in medicine, such as industriousness and ambitiousness, but can also produce individuals who indiscriminately say "yes" to every opportunity offered until it threatens one's personal well-being, a cycle that has been termed the trap of achievement. ${ }^{12}$
When taking on an extracurricular role or project, residents ought to ask themselves whether it will result in both achievement and fulfillment. Achievement is derived from external validation, whereas fulfillment arrives from internal satisfaction. ${ }^{12}$ Academic physicians should aim to spend at least $10 \%$ to $20 \%$ of their time pursuing fulfillment to avoid high levels of burnout. $^{13}$

Learning to say "no" is a valuable skill and can protect one from burnout. Within the medical hierarchy, this decision can be particularly difficult when an invitation comes from a superior. If a resident finds himself or herself in a situation where he or she would like to decline the opportunity, we suggest practical communication strategies to phrase the response tactfully, while keeping relationships intact (Table 1).

\section{CONCLUSION}

Taher et al. have described a landmark set of recommendations that will help build a culture of wellness in residency. The current climate of residency education is ripe for harnessing the momentum of wellness initiatives to create lasting change, and we aim to have provided some practical steps for residents and educators. The time to act is now.

Keywords: emergency medicine, medical education, professional burnout, psychological resilience, residency

Competing interests: None declared.

\section{REFERENCES}

1. Canadian Medical Association. CMA Workforce Survey 2017; 2017. Available at: http://cma.andornot.com/en/sur veydata/default.aspx (accessed July 9, 2018). 
2. Freudenberger HJ. Staff burn-out. 7 Soc Issues 1974;30 (1):159-65.

3. Atkinson P, Ducharme J, Campbell S. C7EM Debate Series: \#Burnout - Burnout is inevitable in clinical emergency medicine practice. CFEM 2017;19(5):386-9.

4. Ross S, Liu EL, Rose C, et al. Strategies to enhance wellness in emergency medicine residency training programs. Ann Emerg Med 2017;70(6):891-7.

5. Ishak WW, Lederer S, Mandili C, et al. Burnout during residency training: a literature review. 7 Grad Med Educ 2009;1(2):236-42.

6. Taher A, Crawford S, Koczerginski J, et al. Position statement on resident wellness. CFEM 2018;20(5):671-84.

7. Fernando SM, Cheung WJ, Choi SB, et al. Faculty mentorship during residency and professional development among practising emergency physicians. C7EM 2018;epub, doi: $10.1017 / \mathrm{cem} .2018 .42$

8. Calder-Sprackman S, Kumar T, Gerin-Lajoie C, et al. Ice cream rounds: The adaptation, implementation, and evaluation of a peer-support wellness rounds in an emergency medicine resident training program. CFEM 2018;20(5):777-80.

9. Ting DK. A good death is hard to find. CFEM 2017;19 (5):390-1.

10. Carroll LR. The other side of the curtain. CFEM 2018;20 (3):461-2.

11. Gray S. Failing up and failing better. CanadiEM; 2017. Available at: https://canadiem.org/failing-failing-better/ (accessed July 15, 2018).

12. Orman R. Finding the joy. Podcast. ERCast; 2017. December 8, 2017. Available at: https://radiopublic.com/ ercast-GMlvle/ep/s1!09677a9423e9c111c19c0ad9ee96f9631 297c772 (accessed July 11, 2018).

13. Linzer M, Levine R, Meltzer D, et al. 10 bold steps to prevent burnout in general internal medicine. 7 Gen Intern Med 2014;29(1):18-20.

14. Stone D, Heen S. Thanks for the feedback. New York, NY: Viking Penguin; 2014. 